\title{
Oncogenes, mitochondrial metabolism, and quality control in differentiated thyroid cancer
}

\author{
Hyon-Seung $\mathrm{Yi}^{1}$, Joon Young Chang ${ }^{1,2}$, Koon Soon $\mathrm{Kim}^{1}$, and Minho Shong ${ }^{1}$
}

\begin{abstract}
${ }^{1}$ Research Center for Endocrine and Metabolic Diseases, ${ }^{2}$ Department of Medical Science, Chungnam National University School of Medicine, Daejeon, Korea
\end{abstract}

Received: December 14, 2016 Accepted: March 7, 2017

\section{Correspondence to \\ Minho Shong, M.D.}

Research Center for Endocrine and Metabolic Diseases, Chungnam National University School of Medicine, 266 Munhwa-ro, Jung-gu, Daejeon 35015, Korea Tel: $+82-42-280-6994$

Fax: +82-42-280-7995

E-mail: minhos@cnu.ac.kr
Thyroid cancer is one of the most common malignancies of endocrine organs, and its incidence rate has increased steadily over the past several decades. Most differentiated thyroid tumors derived from thyroid epithelial cells exhibit slow-growing cancers, and patients with these tumors can achieve a good prognosis with surgical removal and radioiodine treatment. However, a small proportion of patients present with advanced thyroid cancer and are unusually resistant to current drug treatment modalities. Thyroid tumorigenesis is a complex process that is regulated by the activation of oncogenes, inactivation of tumor suppressors, and alterations in programmed cell death. Mitochondria play an essential role during tumor formation, progression, and metastasis of thyroid cancer. Recent studies have successfully observed the mitochondrial etiology of thyroid carcinogenesis. This review focuses on the recent progress in understanding the molecular mechanisms of thyroid cancer relating to altered mitochondrial metabolism.

Keywords: Thyroid neoplasms; Oncogenes; Mitochondria; Metabolism

\section{INTRODUCTION}

Thyroid cancer is one of the most common malignancies of endocrine organs, and its incidence rate has steadily increased over the past several decades [1]. From the late 1940 s on, the number of research articles on thyroid cancer has continuously increased, although there has been no significant difference in the number of thyroid cancer articles as a percentage of all research articles (Fig. 1). From the late 1980 s to 2000 , the discovery and functional validation of oncogenes stimulated an increase in articles related to several important oncogenes that also play a critical role in thyroid tumorigenesis (Fig. 2). The number of articles exploring the relationship between thyroid cancer and mitochondria increased during the 1970s, and has increased again since the early 2000 s.

The thyroid gland contains two distinct types of ep- ithelial cells, designated as follicular and parafollicular cells. Although both cell types may develop into distinct cancers, more than $95 \%$ of thyroid cancers originate from follicular epithelial cells. Most differentiated thyroid tumors derived from thyroid epithelial cells exhibit slow-growing cancers, and patients with these tumors can achieve a good prognosis with surgical removal and radioiodine treatment $[1]$.

The recent progress in understanding the molecular mechanisms of thyroid cancers has promoted the development of effective treatment modalities [2]. This has resulted from the discovery of molecular events including germline or somatic mutations, genetic rearrangements, and epigenetic alterations that constitutively stimulate signaling pathways such as the mitogen-activated protein kinase (MAPK) and phosphatidylinositol-3-kinase $\left(\mathrm{PI}_{3} \mathrm{~K}\right)$-Akt pathways [2]. Tumorigenesis is a complex process that is regulated by the activation of oncogenes, 

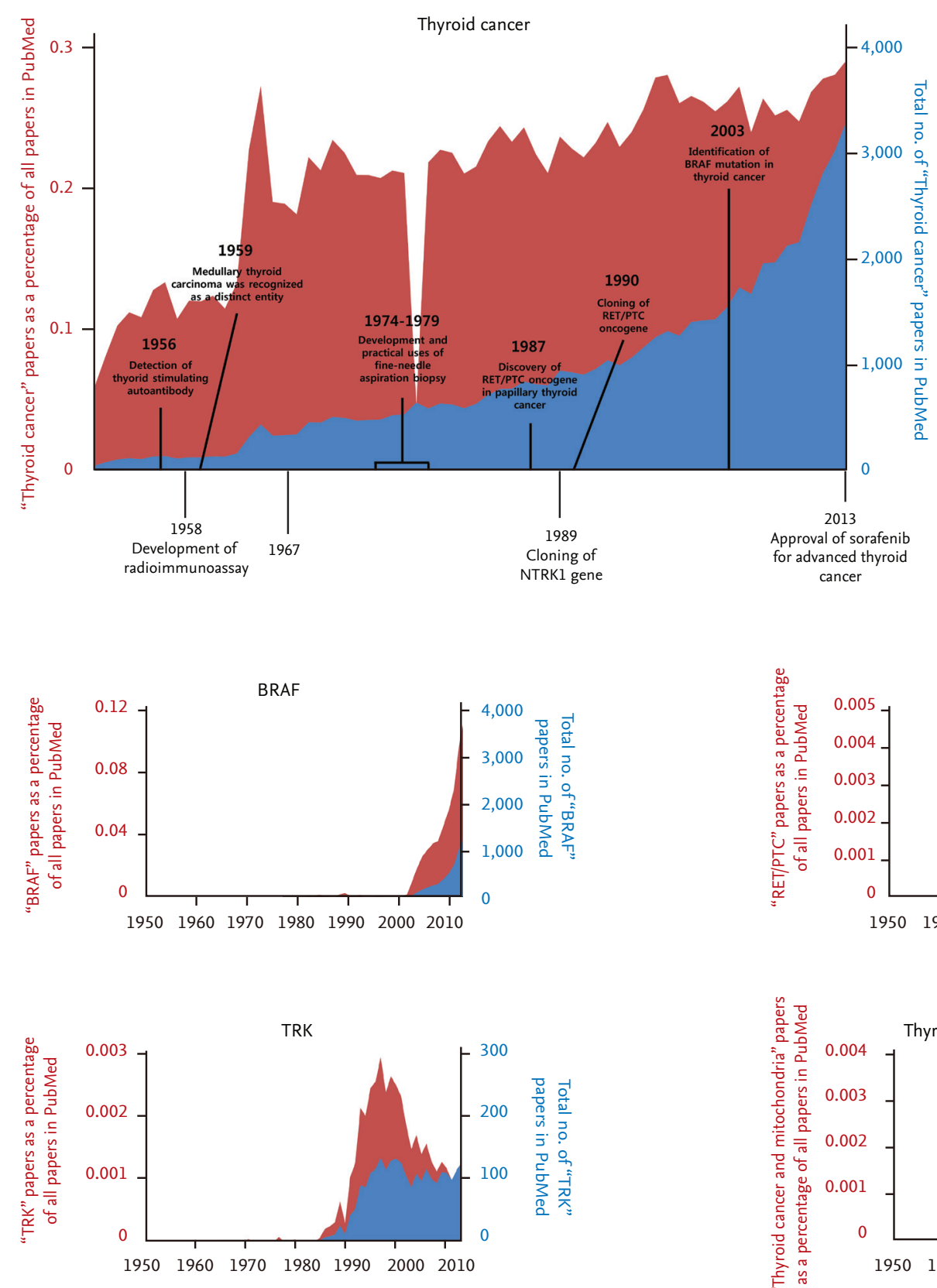

Figure 1. Scientific interest in thyroid cancer from the 1950 s to the present. Articles were identified in PubMed using the term "thyroid cancer" for each year from 1950 to 2014, and are expressed as the total number of thyroid cancer articles, and thyroid cancer articles as a percentage of all articles. Important milestones in the field of thyroid cancer research are indicated by the year of publication. PTC, papillary thyroid cancer; BRAF, B-Raf; NTRK1, neurotrophic receptor tyrosine kinase 1.
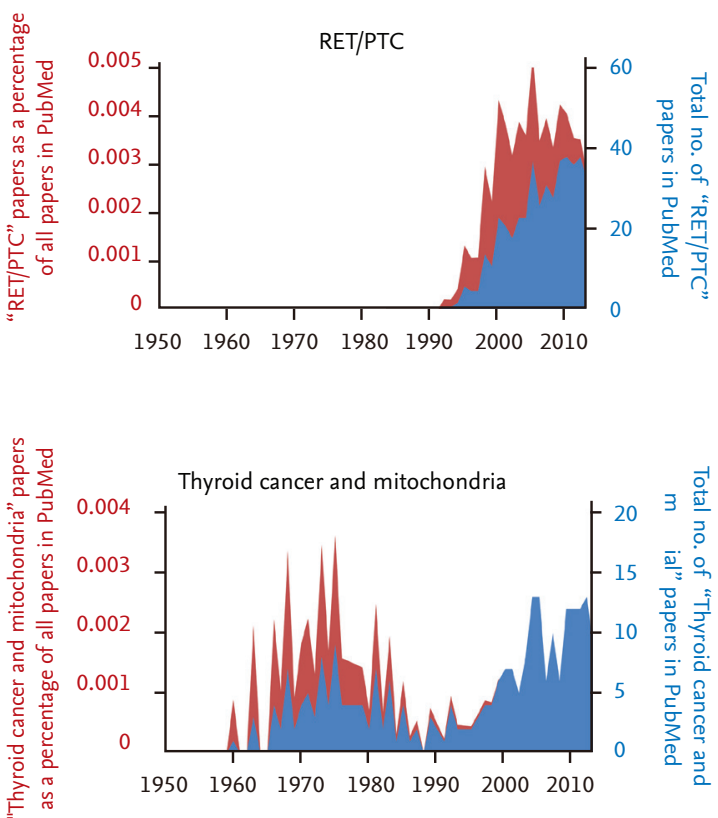

Figure 2. Total number and percentage of (A) BRAF, (B) RET/PTC, (C) TRK, and (D) thyroid cancer and mitochondria articles in PubMed. BRAF, B-Raf; PTC, papillary thyroid cancer; TRK, tropomyosin receptor kinase.

inactivation of tumor suppressors, and reprogramming of cell death [3]. Mitochondria also play an essential role in tumorigenesis as vital organelles responsible for energy production, generation of radical oxygen species (ROS), calcium homeostasis, and the regulation of apoptotic signaling [4]. Cancer cell proliferation and resistance is regulated by these mitochondrial properties during the development of cancer. Mitochondrial energy metabolism is implicated in the alteration of energy production in tumor cells. Additionally, recent studies show that mitochondrial quality control through autophagy and mitophagy is associated with the growth of tumors, including thyroid cancer tumors $[5,6]$.

This review focuses on the recent remarkable progress 
in understanding the molecular mechanisms of thyroid cancer, and discusses the role of altered mitochondrial metabolism in the development of thyroid cancer.

\section{GENETIC ALTERATIONS IN THYROID CANCER}

Genomic mutations or rearrangements regulating growth-stimulating signaling pathways appear to be involved in the transformation process in well-differentiated thyroid cancers $[7,8]$. A prominent mutation is the $\mathrm{V} 600 \mathrm{E}$ point mutation of $\mathrm{B}-\mathrm{Raf}$ (BRAF), which constitutively activates this serine/threonine kinase [9]. $\mathrm{BRAF}^{\mathrm{V} 600 \mathrm{E}}$ mutations in papillary thyroid cancer (PTC) cell lines are indispensable for tumor initiation, proliferation, and tumorigenicity [10]. $\mathrm{BRAF}^{\mathrm{V} 600 \mathrm{E}}$ transgenic mice also develop a more aggressive phenotype through the regulation of the MST1 (macrophage stimulating 1)- $\mathrm{FOXO}_{3}$ (forkhead box $\mathrm{O}_{3}$ ) signaling pathway in PTC [11]. One study showed that the $\mathrm{BRAF}^{\mathrm{V} 600 \mathrm{E}}$ mutation is detected in nearly $45 \%$ of PTCs [12]. The BRAF ${ }^{\mathrm{V} 600 \mathrm{E}} \mathrm{mu}$ tation is strongly associated with poor clinicopathologic outcomes including mortality, lymph node metastasis, and distant tumor metastasis among patients with PTC [13]. Moreover, other studies also support the effect of the $\mathrm{BRAF}^{\mathrm{V} 600 \mathrm{E}}$ mutation on poor prognosis in patients with PTC [14]. However, overall mortality is very low in PTC and questions still remain as to how best to utilize information regarding the $\mathrm{BRAF}^{\mathrm{V} 600 \mathrm{E}}$ mutation in managing mortality risk.

Ras mutations are also prevalent in thyroid cancer. Ras is a member of the $G$ protein families, which bind GDP (guanosine diphosphate, inactive form). or GDP (guanosine diphosphate, inactive form). Mutations are known to induce the loss of Ras GTPase activity; thereby, locking Ras in a constitutively active GTP-bound form. Of the three mammalian Ras genes (HRas, KRas, and NRas), NRas is predominantly mutated in thyroid cancers, mostly showing mutations in codons 12 and 61 . Ras mutations activate the MAPK and $\mathrm{PI}_{3} \mathrm{~K}$-Akt signaling pathways in thyroid tumorigenesis [15]. Ras mutations are also common in follicular thyroid adenoma, a premalignant lesion, indicating a role in early follicular thyroid cell tumorigenesis [16]. However, the HRas mutation is found in normal thyroid cells in vitro, and is associated with well-demarcated and differentiated col- onies with phenotypes consistent with follicular thyroid adenoma and cellular proliferation with normal differentiation [17].

Balanced inversions or translocations resulting in oncogenic rearrangement, which usually involve the $3.0 \mathrm{kB}$ intron 11 of the tyrosine kinase receptor protein RET, are found in thyroid cancer. In other words, RET-PTC rearrangements occur as a result of genetic recombination between the 3 ' tyrosine kinase portion of RET and the 5' portion of a partner gene. RET-PTC reportedly results in ligand-independent dimerization and constitutive tyrosine kinase activity in thyroid epithelial cells. Although RET-PTC has intrinsic tyrosine activity and occurs in thyroid tumors, the direct substrate of RETPTC in thyroid cells remains unknown. Previously, our group showed that phosphoinositide-dependent kinase 1 (PDK1), an essential serine/threonine kinase in growth factor signaling pathways, is a target of RET/PTC. RETPTC and PDKı are colocalized in the cytosol, and RETPTC phosphorylates a specific tyrosine $\left(\mathrm{Y}_{9}\right)$ residue located in the N-terminal portion of PDK1. RET-PTCinduced tyrosine phosphorylation of PDKı is one of the mechanisms by which it acts as an oncogenic tyrosine kinase in thyroid tumorigenesis [18]. Additionally, RETPTC also phosphorylates a $\mathrm{Y}_{315}$ residue in protein kinase $\mathrm{B}$ (PKB), which is known to be phosphorylated by the Src tyrosine kinase. This event activates PKB downstream signaling pathways; thereby, inducing thyroid carcinogenesis [19].

RET-PTC also interacts with signal transducer and activator of transcription 3 (STAT 3 ), and phosphorylation activity of RET-PTC on a specific residue (Y705) of $\mathrm{STAT}_{3}$ is a critical signaling event for the induction of genes in the RET-PTC-mediated transformation in thyroid carcinogenesis in vitro [20]. An immunoprecipitation experiment showed an interaction between liver kinase $\mathrm{B} 1$ (LKB1) and STAT3. Moreover, LKB1 and activated $\mathrm{STAT}_{3}$ were colocalized within the nucleus of the cell. Furthermore, LKB1 reduces STAT3 transcriptional activity in RET-PTC transfected cells. Thus, we suggested that LKB1 suppresses tumor growth as a transcriptional co-repressor of oncogenic STAT3, which is activated by RET-PTC [21]. Additionally, the expression of phospholipase $\mathrm{D}$ is increased in papillary thyroid carcinoma. Transcriptional activity of STAT3 induced by RET-PTC is enhanced by overexpression of phospholi- 
pase D; thereby, indicating that phospholipase D plays a synergistic role in regulating the RET-PTC-induced $\mathrm{STAT}_{3}$ activation during thyroid carcinogenesis [22]. Thyroid stimulating hormone (TSH)-mediated STAT3 activation is associated with SOCS (suppressor of cytokine signaling)-1 and -3 induction, which play a role in the resistance of the thyroid cells to interferon $\gamma$ during the thyrocyte growth phase [23]. TSH receptor-activated $\mathrm{PI}_{3} \mathrm{~K}$ signaling induced by $\mathrm{S} 6 \mathrm{~K} 1$ (S6 kinase beta-1) modulates thyrocyte proliferation and thyroid follicle activity [24]. Moreover, in a recent study, SU11248, which is a multi-target tyrosine kinase inhibitor, induced a complete morphological reversion of transformed NIHRET/PTC3 cells and inhibited the growth of TPC-1 (two pore segment channel 1) cells that have endogenous RET-PTC1 [25]. RET-PTC can also phosphorylate and activate STAT1. This may lead to increased expression of major histocompatibility complex (MHC) class II, which may explain why the tissues surrounding RET-PTC-positive cancers are infiltrated with lymphocytes [26].

Other important genes that are responsible for thyroid tumorigenesis include $\mathrm{p} 53$, phosphatase and tensin homolog (PTEN), $\beta$-catenin, isocitrate dehydrogenase 1, anaplastic lymphoma kinase, and epidermal growth factor receptor [27-32]. The paired box 8-peroxisome proliferator-activated receptor $\gamma(\operatorname{PPAR} \gamma)$ fusion gene is also another recombinant oncogene in follicular thyroid carcinoma [33]. Moreover, the AKAP9 (A-kinase anchor protein 9)-BRAF fusion gene results in an increase in BRAF kinase activity, associated with ionizing radiation-induced PTC, but not with sporadic PTC [34]. Oncogenic kinases involved in papillary thyroid carcinoma trigger the expression of class II transactivator and MHC class II complex [35]. Additionally, the expression of the Gadd $45 \gamma$ (growth arrest and DNA damage-inducible gene family $45 \gamma$ ) gene, which has been implicated in a variety of growth-regulatory mechanisms, is significantly decreased in anaplastic thyroid cancer cell lines. Re-expression of Gadd $45 \gamma$ suppressed anaplastic thyroid cancer cell growth, reminiscent of the effects of p53 [36]. Acquisition of functional CXCR4 (C-X-C chemokine receptor type 4) expression is involved in local invasion by autocrine and paracrine SDF-1 $\alpha$ (stromal cell-derived factor-1 $\alpha$ ) stimulation during the process of carcinogenesis in anaplastic thyroid cancer [37]. Although most of these genetic alterations are common in thyroid cancer, genetic alterations have not been characterized in approximately $30 \%$ of differentiated thyroid carcinomas. Therefore, further studies are necessary for determining the underlying genetic mechanisms of thyroid tumorigenesis.

\section{MITOCHONDRIAL METABOLISM IN TUMORI- GENESIS}

The energy metabolism of most cancer cells differs markedly from that of normal cells in order to meet energy demands during tumor progression [38]. It has become clear that cellular energy metabolism controlled by oncogenes and other tumor-related factors is a critical factor determining the clinical phenotypes of cancer. Our understanding of the molecular carcinogenesis of thyroid cancer has notably advanced over the last decade. However, the role and nature of energy metabolism in thyroid cancer remains to be identified.

Mitochondria provide $90 \%$ of the cellular energy required for various biological functions through oxidative phosphorylation in the inner mitochondrial membrane [39]. In addition, mitochondria regulate various cellular processes, including steroid hormone and porphyrin synthesis, the urea cycle, lipid metabolism, and the interconversion of amino acids [40]. Mitochondria also play central roles in apoptosis, cellular proliferation, and cellular $\mathrm{Ca}^{2+}$ homeostasis, which affect numerous cellular signaling pathways. Taken together, mitochondria play an important role in the energy metabolism of the normal thyroid gland as well as in thyroid tumors. The consequences of mitochondrial functional and structural alterations in thyroid tumorigenesis and tumor progression will be further explored in the next section.

\section{Mitochondrial DNA alterations in thyroid cancer}

The genetic basis of cancer progression has already been studied extensively and will not be covered in depth in this review. Increases in the somatic or germline mutation frequency induced by DNA repair defects, replication errors, chemical or radiation exposure, or the aging process have been reported to lead to cancer [41]. In contrast, the role of mitochondrial genomic mutations in the development of thyroid cancer has not been well 
studied. The majority of mitochondrial proteins are encoded by nuclear DNA, with only 37 genes encoded by mitochondrial DNA (mtDNA). These include 13 components of the electron transport chain, 22 transfer RNAs, and two ribosomal RNAs. MtDNA mutations influencing mitochondrial metabolism and biogenesis have been found in a variety of cancers [42-47]. Several studies have shown that acquired mtDNA alterations are associated with thyroid cancer. It has been known for over three decades that thyroid tumors contain abnormally high numbers of mitochondria. A common mutational mechanism in thyroid cancer is somatic point mutations of mtDNA. The majority of the mutations were found in mitochondrial complex I of the respiratory chain, and severe functional defects in complex I activity were observed in thyroid tumor cell lines [48]. These studies suggest that somatic mtDNA mutations may be associated with tumor development in the thyroid gland. Disruptive mtDNA mutations in complex I of the respiratory chain are also markers for oncocytic thyroid tumors and may promote the accumulation of abnormal mitochondria [49]. Moreover, mitochondrial dysfunction in the oncocytic thyroid cell line XTC.UC1 can be attributed to combined complex I/III defects associated with mtDNA mutations [50]. A study of 79 benign and malignant thyroid tumors revealed that mtDNA deletions were detected in $100 \%$ of Hürthle cell tumors, $33.3 \%$ of adenomas, and in $18.8 \%$ of non-Hürthle cell papillary carcinomas [51]. Additionally, the number of mtDNA deletions was strongly correlated with the level of mtDNA content in tumor tissues in radiation-related human PTC and follicular adenoma [52].

\section{Mitochondrial biogenesis and metabolism in thy- roid cancer}

Mitochondrial biogenesis is a complex and multistep cellular process resulting in the addition of new mitochondrial material within a cell. Emerging evidence shows that it is also associated with carcinogenesis in thyroid cancer as well as other types of tumors. Oncocytomas are defined by an abnormal proliferation of mitochondria, and have an effect on a variety of human tissues. Thyroid oncocytomas, also known as Hürthle cell tumors, are characterized by the presence of abundant oxyphilic granular cytoplasm in at least $75 \%$ of the oncocytes due to the accumulation of numerous abnor- mal mitochondria [53,54]. Oncocytic changes in thyroid follicular cells are frequently detected in obese mice and humans, and abnormal mitochondria have been observed in the thyroids of obese mice [55]. Mitochondrial biogenesis is regulated by nitric oxide (NO) and calcium via PGC-1-related coactivator (PRC) in human follicular thyroid carcinoma cell lines [56]. NO also controls mitochondrial biogenesis through the cGMP (cyclic guanosine monophosphate)/PRC pathway in a cellular model of oncocytic thyroid tumors [57]. Mitochondrial dynamics are indispensable for thyroid oncocytic cell tumors and play an important role in the development of the malignant phenotype. Proteins governing mitochondrial dynamics, such as mitofusin 2 (MFN2), optic atrophy 1 (OPA1), dynamin-related protein 1 (DRP1), and mitochondrial fission 1 (FIS1), are overexpressed in oncocytic cell tumors [58]. Among these proteins, the expression of Mfn2 and the pro-fission protein Drp1 were found to be positively associated with malignant oncocytic thyroid tumors [58]. Furthermore, a blockade of Drp1 is sufficient to decrease oncocytic cell migration and invasion [58].

\section{Mitochondrial function in oncogenic action in thy- roid cancer}

Molecular events associated with the development of thyroid cancer include activation of the RET/PTC and TrkA (tropomyosin receptor kinase A) tyrosine kinase receptors, activation of Ras genes, inactivation of the p53 gene, Pax8, and PPAR $\gamma 1$ rearrangements, and the active conformation of $\mathrm{BRAF}^{\mathrm{V} 600 \mathrm{E}}$ [2]. The activation of the RET/PTC oncogene is prevalent in Hürthle cell thyroid adenomas and carcinomas [59]. RET/PTC rearrangement-induced $\mathrm{STAT}_{3}$ activation is also frequently observed in cancer cells [20] and has been implicated as a regulator of cellular metabolism in tumor formation [6o]. Moreover, STAT3 phosphorylated at serine 727 has been shown to localize in the mitochondria, where it positively regulates the activity of mitochondrial complex I/II [61]. LKB1 suppresses RET/PTC-dependent activation of $\mathrm{STAT}_{3}$ and represses the binding of $\mathrm{STAT}_{3}$ to its target promoters; thereby, decreasing the expression of downstream target genes of $\mathrm{STAT}_{3}$ in a human thyroid cancer cell line [21]. However, the tumor-promoting role of $\mathrm{STAT}_{3}$ has been challenged by several studies [62-64]. STAT3 knockdown in a thyroid cancer 
cell line and a murine model of $\mathrm{BRAF}^{\mathrm{V} 600 \mathrm{E}}$-induced PTC increased cellular proliferation and tumor growth [65]. The mitochondrial localization observed in oncogenic BRAF mutants may be related to the altered responses to apoptotic stimuli and characteristic metabolic phenotypes found in thyroid cancer [66].

The presence of activated mutant Ras in thyroid tumors, including benign follicular adenomas, follicular carcinomas, and papillary carcinoma, has been known for several decades [67]. Ras proteins play an essential role in the activation of the MAPK and $\mathrm{PI}_{3} \mathrm{~K}$-Akt signaling pathways in thyroid cancer, which mediate cellular proliferation and survival $[68,69]$. Although Ras is a dual activator of both the MAPK and $\mathrm{PI}_{3} \mathrm{~K}$-Akt signaling pathways, Ras mutations primarily activate the $\mathrm{PI}_{3} \mathrm{~K}$-Akt pathway in thyroid tumorigenesis [15,70]. Activation of $\mathrm{PI}_{3} \mathrm{~K}-$ Akt induces aberrant methylation and, thus, silencing of PTEN; thereby, leading to a failure to suppress $\mathrm{PI}_{3} \mathrm{~K}-$ Akt signaling and thyroid tumor progression [71]. The Ras oncoprotein is also involved in altering mitochondrial function, genes, and ROS production [72,73]. K-Ras overexpression induces a rapid reduction of complex I and a decrease in mitochondrial membrane potential; thereby, leading to a switch from oxidative phosphorylation to glycolysis, which promotes tumorigenesis [74]. Moreover, mitochondrial STAT3 seems to contribute to Ras-dependent transformation by increasing electron transport chain activity [61].

The most frequently mutated tumor suppressor gene in human cancers is p53. It rapidly translocates to the mitochondrial outer membrane during p53-dependent apoptosis, which is associated with changes in mitochondrial membrane potential, cytochrome $\mathrm{C}$ release, and caspase activation [75]. In contrast, mitochondrial respiratory dysfunction also alters p$_{53}$ expression and transcriptional activity, which consequently impairs p53-mediated cell death [76]. Impairment of p53 caused by germline variants in mitochondrial complex II-succinate dehydrogenase enhances the risk of thyroid cancer in Cowden and Cowden-like syndromes by altering FAD/NAD (flavin adenine dinucleotide/nicotinamide adenine dinucleotide) levels, which are linked to the destabilization of p53 [77].

\section{Mitochondrial quality control and mitophagy in thyroid cancer}

Biogenesis and mitophagy work in concert to regulate mitochondrial mass, function, and quality. Mitophagy is a specialized form of autophagy that selectively degrades and eliminates superfluous or damaged mitochondria.

Oncocytes (Hürthle cells or Askanazy cells) are recognized as a subset of cells characterized by an abundant cytoplasm in which functionally defective mitochondria aberrantly accumulate. Researchers recently found alterations in mtDNA that may perturb oxidative phosphorylation, and speculated about a compensatory organelle biogenesis [51]. It is conceivable that mitophagy is critically linked with the development of oncocytes, a prominent feature of Hürthle cell tumors in the human thyroid gland. We have previously reported that the induction of autophagy and autophagosome formation are common features of oncocytes in Hürthle cell tumors. However, the accumulation of defective mitochondria in oncocytes may be caused by the inability of mitophagy to sufficiently remove abnormal mitochondria.

The PTEN-induced putative kinase 1 (PINK1)-Parkin pathway plays a critical role in the maintenance of mitochondrial quality control by triggering the mitophagy of abnormal mitochondria $[5,6]$. Studies performed in the Hürthle cell-derived XTC.UC1 cell line showed that effective mitochondrial localization of Parkin in response to carbonyl cyanide $m$-chlorophenylhydrazone (CCCP) treatment was impaired, indicating inefficient mitophagy. These results suggest that XTC.UC1 cells have an intact process of non-selective autophagy, but may have defects in mitophagy regulated by PINKı and Parkin. Low immunoexpression of PINK1 and Parkin was detected in Hürthle cell tumors. Surprisingly, in XTC.UC1 cells, Parkin failed to efficiently translocate into mitochondria following CCCP treatment, which is a critical molecular step in PINK1-mediated mitophagy. Based on these findings, the ineffective turnover of abnormal mitochondria in XTC.UC1 cells may be caused by inefficient mitochondrial translocation of Parkin, associated with decreased ligase activity of mutant Parkin in mitochondria [78].

In sum, oncocytes found in Hürthle cell tumors showed ineffective turnover of abnormal mitochondria that may be due to decreased $\mathrm{E}_{3}$ ligase activity associated with dysfunctional translocation of Parkin into mito- 
chondria. In addition, some patients with Hürthle cell tumors harbored a tumor-specific mutation in Parkin $\left(\mathrm{V}_{3} 8 \mathrm{oL}\right)$, and this may explain why oncocytes form in a specific group of heterogeneous Hürthle cell tumors [78].

\section{CONCLUSIONS}

The current challenges lie in identifying the mechanisms modifying oncogenic potentials, which are driven by oncogenic factors, particularly those that mediate transformation, progression, and invasion. Mitochondrial energy metabolism is implicated in the alteration of energy production in tumors. Moreover, active mitochondrial remodeling and adaptation in tumor cells may control the tumor microenvironment and also affect molecular characteristics of the heterogeneity of tumor cells. Additionally, in recent studies, mitochondrial quality control by autophagy and mitophagy seems to be associated with tumor growth, including thyroid cancer [78]. These issues must be addressed for the effective control of advanced thyroid cancer, which has no effective treatment modalities at present.

\section{Conflict of interest}

No potential conflict of interest relevant to this article was reported.

\section{Acknowledgments}

This work was supported by the Basic Science Research Program of the National Research Foundation of Korea, funded by the Ministry of Science, ICT, and Future Planning (NRF-2015R1C1A1Ao1052432). Koon Soon Kim was supported by research fund of Chungnam National University in 2014.

\section{REFERENCES}

1. La Vecchia C, Malvezzi M, Bosetti C, et al. Thyroid cancer mortality and incidence: a global overview. Int J Cancer 2015;136:2187-2195.

2. Nikiforov YE. Thyroid carcinoma: molecular pathways and therapeutic targets. Mod Pathol 2008;21 Suppl 2:S37-S43.
3. Hanahan D, Weinberg RA. The hallmarks of cancer. Cell 2000;100:57-70.

4. Wallace DC. Mitochondria and cancer. Nat Rev Cancer 2012;12:685-698.

5. Ashrafi G, Schwarz TL. The pathways of mitophagy for quality control and clearance of mitochondria. Cell Death Differ 2013;20:31-42.

6. Park J, Lee SB, Lee S, et al. Mitochondrial dysfunction in Drosophila PINKı mutants is complemented by parkin. Nature 2006;441:1157-1161.

7. Fusco A, Viglietto G, Santoro M. A new mechanism of BRAF activation in human thyroid papillary carcinomas. J Clin Invest 2005;115:20-23.

8. Santoro M, Melillo RM, Fusco A. RET/PTC activation in papillary thyroid carcinoma: European Journal of Endocrinology Prize Lecture. Eur J Endocrinol 2006;155:645-653.

9. Kimura ET, Nikiforova MN, Zhu Z, Knauf JA, Nikiforov YE, Fagin JA. High prevalence of BRAF mutations in thyroid cancer: genetic evidence for constitutive activation of the RET/PTC-RAS-BRAF signaling pathway in papillary thyroid carcinoma. Cancer Res 2003;63:1454-1457.

10. Liu D, Liu Z, Condouris S, Xing M. BRAF V6ooE maintains proliferation, transformation, and tumorigenicity of BRAF-mutant papillary thyroid cancer cells. J Clin Endocrinol Metab 2007;92:2264-2271.

11. Lee SJ, Lee MH, Kim DW, et al. Cross-regulation between oncogenic BRAF(V6ooE) kinase and the MST1 pathway in papillary thyroid carcinoma. PLoS One 2011;6:e16180.

12. Xing M. BRAF mutation in thyroid cancer. Endocr Relat Cancer 2005;12:245-262.

13. Xing M, Alzahrani AS, Carson KA, et al. Association between BRAF V6ooE mutation and mortality in patients with papillary thyroid cancer. JAMA 2013;309:1493-1501.

14. Xing M. BRAF mutation in papillary thyroid cancer: pathogenic role, molecular bases, and clinical implications. Endocr Rev 2007;28:742-762.

15. Liu Z, Hou P, Ji M, et al. Highly prevalent genetic alterations in receptor tyrosine kinases and phosphatidylinositol 3-kinase/akt and mitogen-activated protein kinase pathways in anaplastic and follicular thyroid cancers. J Clin Endocrinol Metab 2008;93:3106-3116.

16. Vasko V, Ferrand M, Di Cristofaro J, Carayon P, Henry JF, de Micco C. Specific pattern of RAS oncogene mutations in follicular thyroid tumors. J Clin Endocrinol Metab 2003;88:2745-2752.

17. Gire V, Wynford-Thomas D. RAS oncogene activation 
induces proliferation in normal human thyroid epithelial cells without loss of differentiation. Oncogene 2000;19:737-744.

18. Kim DW, Hwang JH, Suh JM, et al. RET/PTC (rearranged in transformation/papillary thyroid carcinomas) tyrosine kinase phosphorylates and activates phosphoinositide-dependent kinase 1 (PDK1): an alternative phosphatidylinositol 3-kinase-independent pathway to activate PDK1. Mol Endocrinol 2003;17:1382-1394.

19. Jung HS, Kim DW, Jo YS, et al. Regulation of protein kinase B tyrosine phosphorylation by thyroid-specific oncogenic RET/PTC kinases. Mol Endocrinol 2005;19:2748-2759.

20. Hwang JH, Kim DW, Suh JM, et al. Activation of signal transducer and activator of transcription 3 by oncogenic RET/PTC (rearranged in transformation/papillary thyroid carcinoma) tyrosine kinase: roles in specific gene regulation and cellular transformation. Mol Endocrinol 2003;17:1155-1166.

21. Kim DW, Chung HK, Park KC, et al. Tumor suppressor LKB1 inhibits activation of signal transducer and activator of transcription 3 (STAT3) by thyroid oncogenic tyrosine kinase rearranged in transformation (RET)/papillary thyroid carcinoma (PTC). Mol Endocrinol 2007;21:3039-3049.

22. Kim YR, Byun HS, Won M, et al. Modulatory role of phospholipase $\mathrm{D}$ in the activation of signal transducer and activator of transcription (STAT)-3 by thyroid oncogenic kinase RET/PTC. BMC Cancer 2008;8:144.

23. Kim H, Suh JM, Hwang ES, et al. Thyrotropin-mediated repression of class II trans-activator expression in thyroid cells: involvement of $\mathrm{STAT}_{3}$ and suppressor of cytokine signaling. J Immunol 2003;171:616-627.

24. Suh JM, Song JH, Kim DW, et al. Regulation of the phosphatidylinositol 3-kinase, Akt/protein kinase B, FRAP/ mammalian target of rapamycin, and ribosomal S6 kinase 1 signaling pathways by thyroid-stimulating hormone (TSH) and stimulating type TSH receptor antibodies in the thyroid gland. J Biol Chem 2003;278:21960-21971.

25. Kim DW, Jo YS, Jung HS, et al. An orally administered multitarget tyrosine kinase inhibitor, SU11248, is a novel potent inhibitor of thyroid oncogenic RET/papillary thyroid cancer kinases. J Clin Endocrinol Metab 2006;91:4070-4076.

26. Hwang ES, Kim DW, Hwang JH, et al. Regulation of signal transducer and activator of transcription 1 (STAT1) and STAT1-dependent genes by RET/PTC (rearranged in transformation/papillary thyroid carcinoma) oncogenic tyrosine kinases. Mol Endocrinol 2004;18:2672-2684.

27. Fagin JA, Matsuo K, Karmakar A, Chen DL, Tang SH, Koeffler HP. High prevalence of mutations of the p53 gene in poorly differentiated human thyroid carcinomas. J Clin Invest 1993;91:179-184.

28. Garcia-Rostan G, Tallini G, Herrero A, D'Aquila TG, Carcangiu ML, Rimm DL. Frequent mutation and nuclear localization of beta-catenin in anaplastic thyroid carcinoma. Cancer Res 1999;59:1811-1815.

29. Gustafson S, Zbuk KM, Scacheri C, Eng C. Cowden syndrome. Semin Oncol 2007;34:428-434.

30. Hemerly JP, Bastos AU, Cerutti JM. Identification of several novel non-p.R132 IDH1 variants in thyroid carcinomas. Eur J Endocrinol 2010;163:747-755.

31. Murugan AK, Dong J, Xie J, Xing M. Uncommon GNAQ, MMP8, AKT 3 , EGFR, and PIK 3 Ri mutations in thyroid cancers. Endocr Pathol 2011;22:97-102.

32. Murugan AK, Xing M. Anaplastic thyroid cancers harbor novel oncogenic mutations of the ALK gene. Cancer Res 2011;71:4403-4411.

33. Eberhardt NL, Grebe SK, McIver B, Reddi HV. The role of the PAX8/PPARgamma fusion oncogene in the pathogenesis of follicular thyroid cancer. Mol Cell Endocrinol 2010;321:50-56.

34. Ciampi R, Knauf JA, Kerler R, et al. Oncogenic AKAP9BRAF fusion is a novel mechanism of MAPK pathway activation in thyroid cancer. J Clin Invest 2005;115:94-101.

35. Jo YS, Lee JC, Li S, et al. Significance of the expression of major histocompatibility complex class II antigen, HLA$\mathrm{DR}$ and $-\mathrm{DQ}$, with recurrence of papillary thyroid cancer. Int J Cancer 2008;122:785-790.

36. Chung HK, Yi YW, Jung NC, et al. Gadd45gamma expression is reduced in anaplastic thyroid cancer and its reexpression results in apoptosis. J Clin Endocrinol Metab 2003;88:3913-3920.

37. Hwang JH, Hwang JH, Chung HK, et al. CXC chemokine receptor 4 expression and function in human anaplastic thyroid cancer cells. J Clin Endocrinol Metab 2003;88:408-416.

38. Ward PS, Thompson CB. Metabolic reprogramming: a cancer hallmark even Warburg did not anticipate. Cancer Cell 2012;21:297-308.

39. Kim SJ, Kwon MC, Ryu MJ, et al. CRIF1 is essential for the synthesis and insertion of oxidative phosphorylation polypeptides in the mammalian mitochondrial membrane. Cell Metab 2012;16:274-283.

40. Brookes PS, Yoon Y, Robotham JL, Anders MW, Sheu SS. 
Calcium, ATP, and ROS: a mitochondrial love-hate triangle. Am J Physiol Cell Physiol 2004;287:C817-C833.

41. Stratton MR, Campbell PJ, Futreal PA. The cancer genome. Nature 2009;458:719-724.

42. Bartoletti-Stella A, Salfi NC, Ceccarelli C, Attimonelli M, Romeo G, Gasparre G. Mitochondrial DNA mutations in oncocytic adnexal lacrimal glands of the conjunctiva. Arch Ophthalmol 2011;129:664-666.

43. Brandon M, Baldi P, Wallace DC. Mitochondrial mutations in cancer. Oncogene 2006;25:4647-4662.

44. Chinnery PF, Samuels DC, Elson J, Turnbull DM. Accumulation of mitochondrial DNA mutations in ageing, cancer, and mitochondrial disease: is there a common mechanism? Lancet 2002;360:1323-1325.

45. Copeland WC, Wachsman JT, Johnson FM, Penta JS. Mitochondrial DNA alterations in cancer. Cancer Invest 2002;20:557-569.

46. Gasparre G, Hervouet E, de Laplanche E, et al. Clonal expansion of mutated mitochondrial DNA is associated with tumor formation and complex I deficiency in the benign renal oncocytoma. Hum Mol Genet 2008;17:986-995.

47. Pereira L, Soares P, Maximo V, Samuels DC. Somatic mitochondrial DNA mutations in cancer escape purifying selection and high pathogenicity mutations lead to the oncocytic phenotype: pathogenicity analysis of reported somatic mtDNA mutations in tumors. BMC Cancer 2012;12:53.

48. Yeh JJ, Lunetta KL, van Orsouw NJ, et al. Somatic mitochondrial DNA (mtDNA) mutations in papillary thyroid carcinomas and differential mtDNA sequence variants in cases with thyroid tumours. Oncogene 2000;19:2060-2066.

49. Gasparre G, Porcelli AM, Bonora E, et al. Disruptive mitochondrial DNA mutations in complex I subunits are markers of oncocytic phenotype in thyroid tumors. Proc Natl Acad Sci U S A 2007;104:9001-9006.

50. Bonora E, Porcelli AM, Gasparre G, et al. Defective oxidative phosphorylation in thyroid oncocytic carcinoma is associated with pathogenic mitochondrial DNA mutations affecting complexes I and III. Cancer Res 2006;66:6087-6096.

51. Maximo V, Soares P, Lima J, Cameselle-Teijeiro J, Sobrinho-Simoes M. Mitochondrial DNA somatic mutations (point mutations and large deletions) and mitochondrial DNA variants in human thyroid pathology: a study with emphasis on Hurthle cell tumors. Am J Pathol 2002;160:1857-1865.
52. Rogounovitch TI, Saenko VA, Shimizu-Yoshida Y, et al. Large deletions in mitochondrial DNA in radiation-associated human thyroid tumors. Cancer Res 2002;62:7031-7041.

53. Berho M, Suster S. The oncocytic variant of papillary carcinoma of the thyroid: a clinicopathologic study of 15 cases. Hum Pathol 1997;28:47-53.

54. Hong JH, Yi HS, Yi S, Kim HW, Lee J, Kim KS. Implications of oncocytic change in papillary thyroid cancer. Clin Endocrinol (Oxf) 2016;85:797-804.

55. Lee MH, Lee JU, Joung KH, et al. Thyroid dysfunction associated with follicular cell steatosis in obese male mice and humans. Endocrinology 2015;156:1181-1193.

56. Le Pennec S, Mirebeau-Prunier D, Boutet-Bouzamondo N, et al. Nitric oxide and calcium participate in the fine regulation of mitochondrial biogenesis in follicular thyroid carcinoma cells. J Biol Chem 2011;286:18229-18239.

57. Raharijaona M, Le Pennec S, Poirier J, et al. PGC-1-related coactivator modulates mitochondrial-nuclear crosstalk through endogenous nitric oxide in a cellular model of oncocytic thyroid tumours. PLoS One 2009;4:e7964.

58. Ferreira-da-Silva A, Valacca C, Rios E, et al. Mitochondrial dynamics protein Drpı is overexpressed in oncocytic thyroid tumors and regulates cancer cell migration. PLoS One 2015;10:e0122308.

59. Chiappetta G, Toti P, Cetta F, et al. The RET/PTC oncogene is frequently activated in oncocytic thyroid tumors (Hurthle cell adenomas and carcinomas), but not in oncocytic hyperplastic lesions. J Clin Endocrinol Metab 2002;87:364-369.

6o. Bromberg JF, Wrzeszczynska MH, Devgan G, et al. Stat3 as an oncogene. Cell 1999;98:295-303.

61. Gough DJ, Corlett A, Schlessinger K, Wegrzyn J, Larner AC, Levy DE. Mitochondrial STAT3 supports Ras-dependent oncogenic transformation. Science 2009;324:1713-1716.

62. de la Iglesia N, Konopka G, Puram SV, et al. Identification of a PTEN-regulated $\mathrm{STAT}_{3}$ brain tumor suppressor pathway. Genes Dev 2008;22:449-462.

63. Musteanu M, Blaas L, Mair M, et al. Stat3 is a negative regulator of intestinal tumor progression in Apc(Min) mice. Gastroenterology 2010;138:1003-1011.

64. Schneller D, Machat G, Sousek A, et al. p19(ARF)/pı(ARF) controls oncogenic functions of signal transducer and activator of transcription 3 in hepatocellular carcinoma. Hepatology 2011;54:164-172.

65. Couto JP, Daly L, Almeida A, et al. STAT3 negatively regulates thyroid tumorigenesis. Proc Natl Acad Sci U S A 
2012;109:E2361-E2370.

66. Lee MH, Lee SE, Kim DW, et al. Mitochondrial localization and regulation of BRAFV6ooE in thyroid cancer: a clinically used RAF inhibitor is unable to block the mitochondrial activities of BRAFV60oE. J Clin Endocrinol Metab 2011;96:E19-E30.

67. Howell GM, Hodak SP, Yip L. RAS mutations in thyroid cancer. Oncologist 2013;18:926-932.

68. Davis RJ. The mitogen-activated protein kinase signal transduction pathway. J Biol Chem 1993;268:14553-14556.

69. Xing M. Genetic alterations in the phosphatidylinositol-3 kinase/Akt pathway in thyroid cancer. Thyroid 2010;20:697-706.

70. Abubaker J, Jehan Z, Bavi P, et al. Clinicopathological analysis of papillary thyroid cancer with $\mathrm{PIK}_{3} \mathrm{CA}$ alterations in a Middle Eastern population. J Clin Endocrinol Metab 2008;93:611-618.

71. Hou P, Ji M, Xing M. Association of PTEN gene methylation with genetic alterations in the phosphatidylinositol 3-kinase/AKT signaling pathway in thyroid tumors. Cancer 2008;113:2440-2447.

72. Chiaradonna F, Gaglio D, Vanoni M, Alberghina L. Expression of transforming K-Ras oncogene affects mito- chondrial function and morphology in mouse fibroblasts. Biochim Biophys Acta 2006;1757:1338-1356.

73. Weinberg F, Hamanaka R, Wheaton WW, et al. Mitochondrial metabolism and ROS generation are essential for Kras-mediated tumorigenicity. Proc Natl Acad Sci U S A 2010;107:8788-8793.

74. $\mathrm{Hu} \mathrm{Y}, \mathrm{Lu} \mathrm{W}$, Chen $\mathrm{G}$, et al. K-ras $(\mathrm{G12V})$ transformation leads to mitochondrial dysfunction and a metabolic switch from oxidative phosphorylation to glycolysis. Cell Res 2012;22:399-412.

75. Marchenko ND, Zaika A, Moll UM. Death signal-induced localization of $\mathrm{p} 53$ protein to mitochondria: a potential role in apoptotic signaling. J Biol Chem 2000;275:16202-16212.

76. Compton S, Kim C, Griner NB, et al. Mitochondrial dysfunction impairs tumor suppressor p53 expression/function. J Biol Chem 2011;286:20297-20312.

77. Ni Y, He X, Chen J, et al. Germline SDHx variants modify breast and thyroid cancer risks in Cowden and Cowdenlike syndrome via FAD/NAD-dependant destabilization of p53. Hum Mol Genet 2012;21:300-310.

78. Lee J, Ham S, Lee MH, et al. Dysregulation of Parkin-mediated mitophagy in thyroid Hurthle cell tumors. Carcinogenesis 2015;36:1407-1418. 